\title{
Hair canopy of cricket sensory system tuned to predator signals
}

\author{
Christelle Magal*, Olivier Dangles, Philippe Caparroy, Jérôme Casas \\ Institut de Recherche sur la Biologie de l'Insecte - UMR CNRS 6035, Faculté des Sciences et Techniques, Université François Rabelais, \\ Parc de Grandmont Avenue Monge, 37200 Tours, France
}

Received 7 August 2005; received in revised form 16 November 2005; accepted 8 December 2005

Available online 20 January 2006

\begin{abstract}
Filiform hairs located on the cerci of crickets are among the most sensitive sensors in the animal world and enable crickets to sense the faintest air movements generated by approaching predators. While the neurophysiological and biomechanical aspects of this sensory system have been studied independently for several decades, their integration into a coherent framework was wanting. In order to evaluate the hair canopy tuning to predator signals, we built a model of cercal population coding of oscillating air flows by the hundreds of hairs on the cerci of the sand cricket Gryllus bimaculatus (Insecta: Orthoptera). A complete survey of all hairs covering the cerci was done on intact cerci using scanning electronic microscopy. An additive population coding of sinusoid signals of varying frequencies and velocities taking into account hair directionality delivered the cercal canopy tuning curve. We show that the range of frequencies and velocities at which the cricket sensory system is best tuned corresponds to the values of signals produced by approaching predators. The relative frequencies of short $\left(<0.5 \times 10^{-3} \mathrm{~m}\right)$ and long hairs and their differing responses to oscillating air flows therefore enable crickets to detect predators in a time-frequency-intensity space both as far as possible and at close range.
\end{abstract}

(C) 2005 Elsevier Ltd. All rights reserved.

Keyword: Biomechanical model; Cercal wind receptor; Insect; Mechanoreceptor; Flying predators

\section{Introduction}

Mechanoreceptive cuticular hairs of Arthropods are among the most sensitive biological sensors in the animal world (Barth, 2002). The best sensing system is found in crickets and other Orthopteroids (e.g. cockroaches) which are equipped with hundreds of filiform hairs responding to air velocities as small as $0.03 \times 10^{-3} \mathrm{~m} \mathrm{~s}^{-1}$, at the limit of the physically possible (Shimozawa et al., 2003). Situated at the abdominal end on a pair of appendices named cerci, filiform hairs are outstandingly used to detect the weakest air signals produced by approaching predators (Gnatzy and Heusslein, 1986). Understanding how predatory air currents trigger almost instantaneous escape response has stimulated extensive research during the last three decades. Cricket evasive behaviour is due to the combination of biomechanical properties of the hairs responding to air movement, physiological properties of the sensory neurons

\footnotetext{
*Corresponding author. Tel.: + 33247366979 .

E-mail address: christelle.magal@univ-tours.fr (C. Magal).
}

and neuronal integration in the periphery (see Jacobs, 1995 for review). This sensing-perception-action sequence enables crickets to efficiently escape toad tongue or flying wasp attacks (Camhi et al., 1978; Gnatzy, 1996).

Lodged in a cuticular socket, each filiform hair can move back and forth up to a maximal value, the socket acting as a stopper. Hair deflection produces a mechanical stress in the cercal afferent neuron under the hair base. This stress is transformed into action potentials that propagate to the abdominal ganglion (Gnatzy and Tautz, 1980; Keil, 1998). The biomechanics of hair movement in an oscillating fluid has been modelled extensively (Shimozawa and Kanou, 1984a; Humphrey et al., 1993, 2003a, b; Osborne, 1996; Shimozawa et al., 1998, 2003). A filiform hair is defined as an inverted pendulum with a rigid shaft supported by a spring at the base (Fig. 1). This mechanical system can be described by four main parameters (Shimozawa et al., 2003): the moment of inertia that represents the mass distribution along the hair shaft; the spring stiffness which provides the restoring torque towards the resting position; the torsional resistance within the hair 


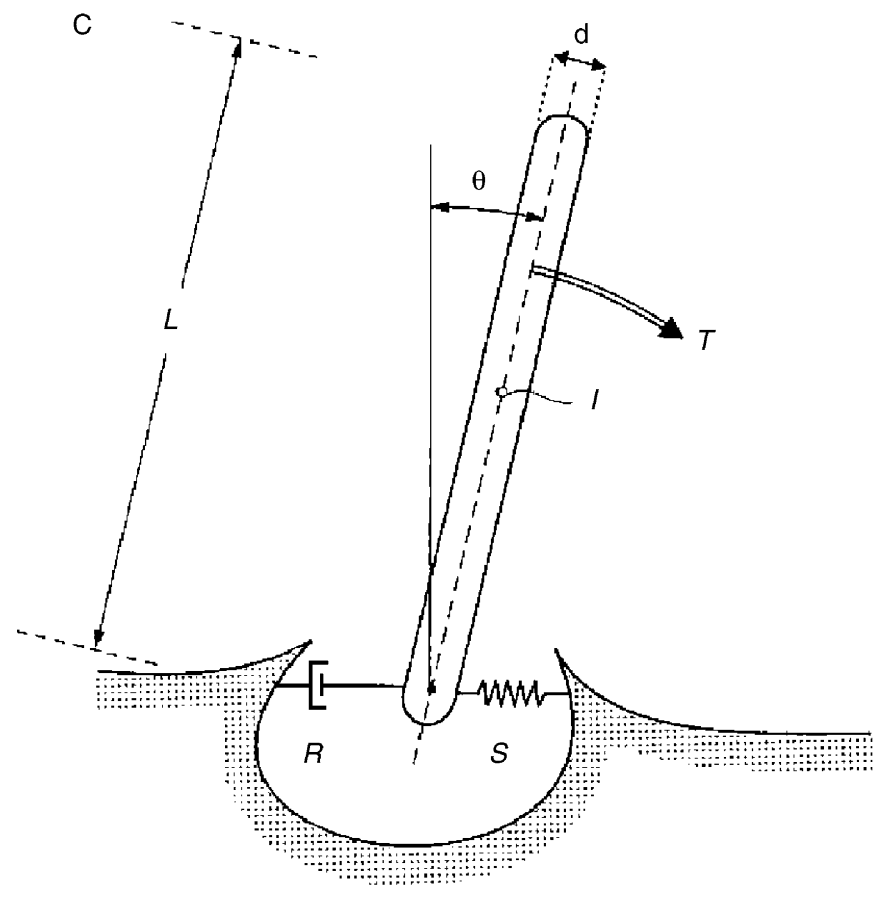

Fig. 1. Schematic drawing of the mechanical structure of a cricket windreceptor hair. Hair shaft with moment of inertia $I$ is supported by a circular diaphragm of joint membrane with spring stiffness $S$. Hair motion is driven by total torque $T$ and causes angular deflection $\theta$ relative to resting position. Kinetic energy of hair motion is dissipated through resistance of tissues within hair base (torsional resistance, $R$ ), and joint membrane spring stiffness. $L$ : hair length; $d$ : hair diameter. The ratio between hair diameter and hair length is exaggerated (after Barth, 2002).

base; and the coupling resistance between hair shaft and the air.

The number of hairs and their variation in length are key features of the cercal system of crickets as they fractionate both the intensity and the frequency range of an air stimulus. Moreover, this sensory system is characterized by the ability of each hair to respond to a preferred air-current direction depending on its constrained plane characteristics (Gnatzy and Tautz, 1980; Landolfa and Jacobs, 1995). Because subsets of the hair canopy have different preferred directions, air movement from any direction deflects only a fraction of the total hair population. Although neuroethologists have pointed at the importance of considering neuronal population coding in fractionating air signals, this knowledge has been developed in total independence from biomechanical studies, and vice versa. Furthermore, complete mapping of filiform hairs on cerci has never been carried out, possibly due to the large amount of work required. This represents however a serious bottleneck to our understanding of cricket air sensing as these insects need to integrate signals over a hair population of varying sizes. We still lack a framework to associate the mechanical behaviour and the neuro-physiological activity of a single filiform hair, and to integrate the summation of these processes over the hair canopy of the entire cercus. This has been achieved for coding population vectors of the directional components of the incoming air flow in the cercal system (Levin and Miller, 1996; Dimitrov and Miller, 2001), an example that has imposed itself as a textbook show case for neural integration (Dayan and Abbott, 2001).

The aim of this study was to build a model that spans the sensing-perception components of the escape sequence in crickets. Our approach proceeded through three successive steps. One step was to build a model that links single hair movement and its neurophysiological activity. In a second step, we implemented the model with experimental length measurements of all hairs located on a cricket cercus. To integrate hair directionality, we calculated in a third step the proportion of hairs responding to an air flow of a given direction. Population coding was done in an additive way, borrowing the approach used for the vector coding in the cricket sensory system (Jacobs, 1995; Johnson, 2003). For each observed hair length class, we weighed the maximal angular deflection by its corresponding frequency. We thereby obtained sensitivity curves of the full cerci as a function of frequency and amplitude, and compared their characteristics to ecologically relevant acoustic signals.

\section{Overall structure of the model}

In order to describe the physical behaviour of a single hair, we combined the models of Shimozawa and Kanou (1984a) and Humphrey et al. (1993). For a rigid hair oscillating relative to a fixed axis of rotation, conservation of angular momentum $L(t)$ states that the rate of change of angular momentum is equal to the sum of torques acting on the hair:

$\frac{\mathrm{d} L(t)}{\mathrm{d} t}=I \frac{\mathrm{d}^{2} \theta}{\mathrm{d} t^{2}}=T_{\mathrm{D}}(t)+T_{\mathrm{VM}}(t)-T_{\mathrm{R}}(t)-T_{\mathrm{S}}(t)$,

where $I$ is the moment of inertia of the hair relative to the axis of rotation and $\theta$ is the angular deflection of the hair with respect to its equilibrium orientation. The drag torque $T_{\mathrm{D}}$ arises due to frictional drag acting along the hair shaft. The torque $T_{\mathrm{VM}}$ is associated with the virtual mass of fluid, which at any instant is related to the relative acceleration of the hair. The damping torque $T_{\mathrm{R}}$ arises at the rotation point of the hair and results from friction between the hair base and the surrounding cuticle. The restoring torque $T_{\mathrm{S}}$ is analogous to the restoring force due to spring stiffness. It expresses the elasticity of the socket membrane and also arises at the rotation point of the hair. The first two torques drive hair motion, whereas the last two always oppose it. We have developed in Appendix A the equations for these four torques following previous authors.

This model is a second-order inhomogeneous ordinary differential equation, which was reduced to an equivalent system of two first-order ordinary differential equations. These equations were numerically solved with respect to the initial conditions of null angular deflection, velocity, and acceleration using the third-order Runge-Kutta 
Table 1

Model parameters

\begin{tabular}{|c|c|c|c|}
\hline Symbols & Parameters & Dimensions & Values \\
\hline$\rho_{\text {air }}$ & Air density & $\mathrm{kg} \mathrm{m}^{-3}$ & 1.1774 \\
\hline$\gamma$ & Euler's constant & No dimension & 0.577 \\
\hline$\mu$ & Air dynamic viscosity & $\mathrm{Ns} \mathrm{m}^{-2}$ & $1.8462 \times 10^{-5}\left(27^{\circ} \mathrm{C}\right)$ \\
\hline$v$ & Air kinematic viscosity & $\mathrm{m}^{2} \mathrm{~s}^{-1}$ & $1.59 \times 10^{-5}$ \\
\hline$D$ & Cercus diameter & $\mathrm{m}$ & $0.4 \times 10^{-3}$ \\
\hline$d$ & Hair diameter & $\mathrm{m}$ & $1 \times 10^{-6}: 15 \times 10^{-6}$ \\
\hline$f$ & Oscillating air flow frequency & $\mathrm{Hz}$ & $0: 300$ \\
\hline$I$ & Hair inertia momentum & $\mathrm{Nm} \mathrm{s} \mathrm{rad}^{-1}$ & \\
\hline$L$ & Hair length & $\mathrm{m}$ & $40 \times 10^{-6}: 1050 \times 10^{-6}$ \\
\hline$R$ & Hair damping constant & $\mathrm{Nms} \mathrm{rad}{ }^{-1}$ & $1 \times 10^{-18}: 4 \times 10^{-14}$ \\
\hline$S$ & Hair restoring constant (spring stiffness) & $\mathrm{Nm} \mathrm{rad}{ }^{-1}$ & $8 \times 10^{-14}: 2 \times 10^{-11}$ \\
\hline$\rho_{\text {hair }}$ & Hair density & $\mathrm{kg} \mathrm{m}^{-3}$ & $1.1 \times 10^{3}$ \\
\hline$U_{0}$ & Oscillating air flow velocity amplitude & $\mathrm{m} \mathrm{s}^{-1}$ & $0.1 \times 10^{-3}: 10 \times 10^{-3}$ \\
\hline$\omega$ & Oscillating air flow angular velocity & $\operatorname{rads}^{-1}$ & \\
\hline
\end{tabular}

method with adaptive stepsize algorithm. Detailed values of model parameters are given in Table 1.

\section{Applying an oscillating flow}

We applied an oscillatory flow mimicking the air movement created by a flying predator approaching from the rear of the cricket to a single hair. We used the model of Stokes (1851), which defines the air flow field as a near-field volume flow wave interacting with an infinite flat substrate. The effect of boundary layer was first mentioned by Shimozawa and Kanou (1984a) and an alternative and more realistic model was fully developed by Humphrey et al. (1993), who considered a spider leg as an infinite cylinder. However, significant differences occurred only for a flow perpendicular to the longitudinal axis of the cercus and the hair behaviour was qualitatively unchanged. We therefore opted for the original model in which the velocity for a fluid oscillating parallel to and far away from a flat surface is given by

$U(t)=U_{0} \sin (\omega t)$

where $U_{0}$ is the flow oscillation amplitude, and $\omega$ is the angular frequency with $\omega=2 \pi f, f$ being the frequency of flow oscillations. This equation represents the air flow in the far field, but the velocity near the substrate is attenuated as follows:

$V_{\mathrm{f}}(t, y)=U_{0}\left(\sin (\omega t)-\sin (\omega t-\beta y) \mathrm{e}^{-\beta y}\right)$

with

$\beta=\left(\frac{\omega}{2 v}\right)^{1 / 2}$,

where $V_{\mathrm{f}}$ is the fluid velocity at time $t$ and at distance $y$ perpendicular from the surface, and $\beta$ is a system parameter. The boundary layer is defined as the location $y=4.5 / \beta$ (Humphrey et al., 1993) from the surface, where viscous damping is detected at $1 \%$ reduction in the amplitude of the far field.

\section{From oscillating hair to action potentials}

The transduction of the hair deflection into electrophysiological activity was modelled using the detailed morphological and physiological studies carried out by Gnatzy and collaborators (Gnatzy and Tautz, 1980; Gnatzy, 1996). Hair deflection is proportional to the strength of the mechanical stimulus and elicits action potentials in the cercal afferent. For simplicity, we assumed that the action potential frequency in the associated cercal afferent is directly proportional to the hair maximal angular deflection. All cercal afferents, regardless of the size of their associated hairs, show tonic response to a burst stimulus of air flow (Kanou and Shimozawa, 1984; Landolfa and Miller, 1995).

Shimozawa and Kanou (1984b) have recorded a neurophysiological activity of cercal afferents only above a given air velocity threshold. We used data presented in their Fig. 5A and B to estimate the relationship between frequency and triggering velocity threshold values for each hair length. Fig. 2 shows that the triggering velocity value, $U^{*}(L)$ is function of the hair length for all hairs, except those longer than $500 \mu \mathrm{m}$. Shimozawa and Kanou (1984b) thus identified two functional categories of hairs. Long hairs $(\geqslant 500 \mu \mathrm{m})$ have low triggering velocity threshold independent on signal frequency. They can be considered as velocity-sensitive hairs.

Short hairs $(<500 \mu \mathrm{m})$ show high triggering velocity thresholds, which are a function of the frequency of air motion following:

$\log \frac{U^{*}(L)}{U_{0}^{*}(L)}=\frac{-s(L)}{20} \log \frac{F}{F_{0}}$,

where $U_{0} *$ is the triggering velocity threshold at the lowest measured frequency $\left(F_{0}=5 \mathrm{~Hz}\right)$ and $s\left(\mathrm{~d} B\right.$ decade $\left.^{-1}\right)$ is the slope of the $\log -\log$ relationship between frequency and threshold velocity. The value of $s$ was estimated from their data as $s(L)=22.32-0.018 L(n=36, r=0.68, p<0.05)$. The short hairs can be considered as acceleration sensitive, 


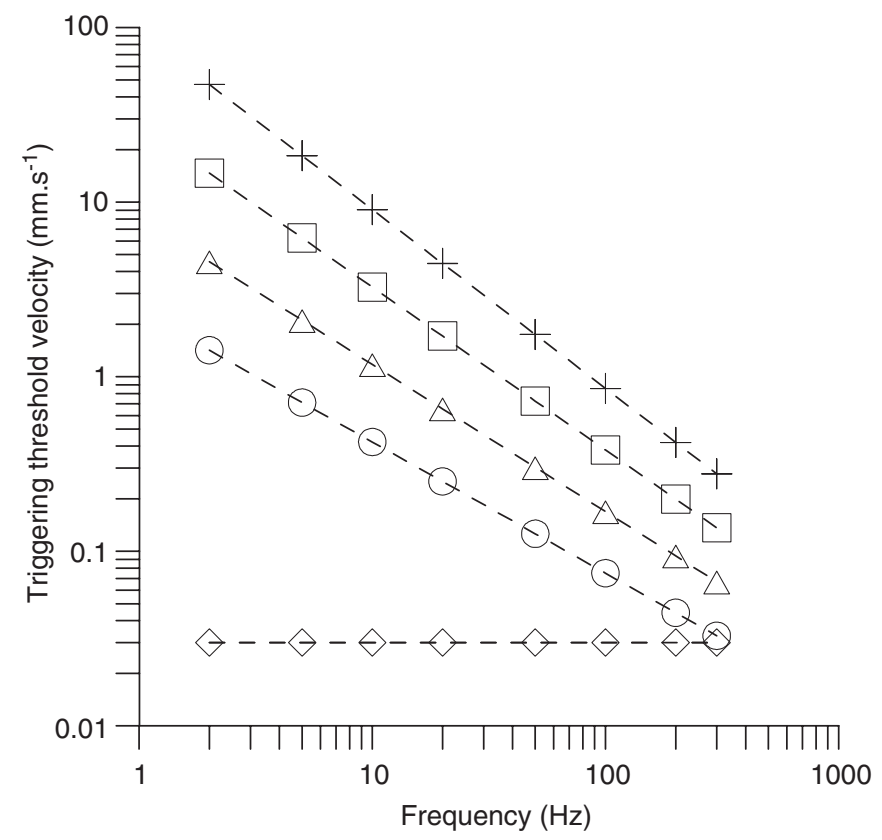

Fig. 2. Velocity threshold of filiform hairs triggering neuronal impulses for varying hair lengths and signal frequencies. From crosses to circles: $100-400 \mu \mathrm{m}$, in $100-\mu \mathrm{m}$ step size isoclines. Diamonds: $L \geqslant 500 \mu \mathrm{m}$. This figure is reconstructed from data in Shimozawa and Kanou (1984b).

since a ten-fold increase in frequency leads to an equivalent decrease in velocity threshold. The relationship between the threshold value at the lowest frequency and hair length was obtained from Shimozawa and Kanou's data as $\log U_{0}^{*}=$ $2.14-0.0061 L(n=26, r=0.71, p<0.05)$.

\section{Experimental estimation of the hair length distribution}

Filiform hair length measurements were conducted on the sand cricket Gryllus bimaculatus, a species found in the Mediterranean region, where it is exposed to a wide array of predators, including flying parasitoids Hymenopterans (Gnatzy, 1996).

Two cerci were dissected and sputter coated with platinum after an acetone wash and air drying. In order to map all filiform hairs with precision, we took a total of 64 pictures all over each cercus surface using a scanning electron microscope (SEM, DSM 982 GEMINI, LEO Microscopie). The cercus was rotated eight times under the microscope. For each angle view $\left(0^{\circ}, 45^{\circ}, 90^{\circ}, 135^{\circ}, \ldots\right)$, we took a set of eight pictures, from the base to the tip of the cercus. Hair length can be precisely estimated from hair base diameter, as there is a strong allometric relationship between these two variables in crickets (Shimozawa and Kanou, 1984b; Kumagai et al., 1998). This was particularly convenient here as hair length measurement is very sensitive to hair orientation on the SEM picture. Based on simultaneous measurements of base diameter $(d)$ and length $(L)$, given both in $\mu \mathrm{m}$, for a series of 40 hairs perfectly located in the photograph plan, we found a significant allometric power function $\left(L=20.21 d^{1.850}\right.$,
$R^{2}=0.83$, Spearman's rank $p<0.001, N=40$ ). We thus measured the base diameter of all hairs over the whole cercus and calculated their length using this relationship.

The measured frequency distribution of overall hair length was decomposed in a number of Gaussian distributions, with different means, variances and proportions using a mixture distribution algorithm ( $\mathrm{R}$ Development Core Team 2003).

Both total number and length distribution of hairs were highly reproducible between the two studied cerci (Kolmogorov-Smirnov test, $p<0.001)$. One cercus of adult $G$. bimaculatus bears around 750 filiform hairs. Measured hairs ranged from $16.4 \times 10^{-6}$ to $1906 \times 10^{-6} \mathrm{~m}$ in length and $0.9 \times 10^{-6}$ to $11.7 \times 10^{-6} \mathrm{~m}$ in base diameter. Hair length frequency distribution showed a strong bimodal aspect revealing the occurrence of two types of hairs (Fig. 3): short hairs $\left(\mu=189 \times 10^{-6} \mathrm{~m} ; \sigma=152 \times 10^{-6} \mathrm{~m}\right)$ and long hairs $\left(\mu=919 \times 10^{-6} \mathrm{~m} ; \quad \sigma=314 \times 10^{-6} \mathrm{~m}\right)$. Short hairs were 2.6 times more abundant than long hairs ( $\mathrm{Pi}=0.72$ vs. 0.28 ).

\section{Population coding: integrating over an entire cercus}

The single hair response to an oscillating flow, its neurophysiological activity and the ensemble reaction due to the numerous hairs on a cercus were integrated in three steps.

First, simulations were performed by applying oscillating flows to a single hair with peak air velocities ranging from $0.2 \times 10^{-3}$ to $10 \times 10^{-3} \mathrm{~m} \mathrm{~s}^{-1}$. For each value of peak air velocity, frequencies ranged from 5 to $300 \mathrm{~Hz}$. Under these

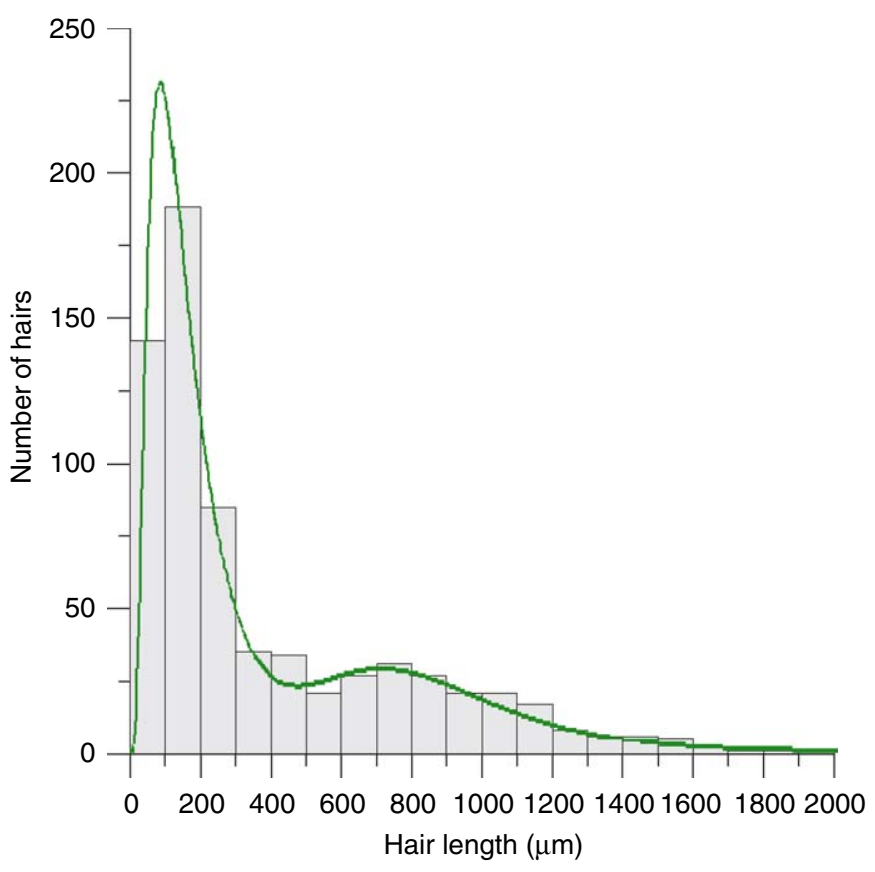

Fig. 3. Complete filiform hair length frequency distribution on whole cricket cerci ( $G$. bimaculatus). The number $k$ of classes was calculated using the Yule formula. The bimodal adjustment was obtained using a mixture distribution algorithm. 
conditions, the values of angular deflection are far below $5^{\circ}$, the approximate value at which the hair movement is stopped by its socket. The frequency response of long hairs of varying lengths is illustrated for a velocity of $0.3 \times 10^{-3} \mathrm{~m} \mathrm{~s}^{-1}$ in Fig. 4. Shorter hairs display a flat response over most of the frequency range, with a peak response at high frequency. The shorter the hair, the lower is the peak value.

Second, for a fixed peak velocity, we retained only those hairs whose maximal deflection was strong enough to trigger neuronal activity (Fig. 2). The maximal hair deflection of a given hair length was then multiplied by the number of observed hairs of that length. We called the obtained sum, $\mathrm{CR}$, the 'canopy response', with radians as units, $\mathrm{CR}=\sum n_{i} \theta_{i}^{\max }$. It represents the sum of the neuronal activity available from each hair.

Third, we calculated the proportion of hairs which have a preferred direction according to the air flow direction. Using Fig. 3 of Landolfa and Jacobs (1995), we estimated that only $24 \%$ of the hair population has a post-lateral preferred direction, therefore responding to air signal coming from the rear. Among them, the proportion of hairs inserted in a cone of $0^{\circ}$ (i.e. completely parallel to the signal), $5^{\circ}, 10^{\circ}, 15^{\circ}$ and $20^{\circ}$ to the air signal is $41 \%, 75 \%$, $92 \%, 98 \%$ and $100 \%$, respectively (Landolfa and Jacobs, 1995, Fig. 1). Thus, the canopy response is equal to

$$
\begin{aligned}
\mathrm{CR}_{\mathrm{cor}}= & \mathrm{CR} * 0.24 *\left[0.41 \cos 0^{\circ}+0.34 \cos 5^{\circ}\right. \\
& \left.+0.17 \cos 10^{\circ}+0.06 \cos 15^{\circ}+0.02 \cos 20^{\circ}\right] \\
= & \mathrm{CR} * 0.236 .
\end{aligned}
$$

A decomposition of the canopy response shows the relative importance of long and short hairs at given frequencies as a function of air velocity. At low air velocities $\left(0.7 \times 10^{-3} \mathrm{~m} \mathrm{~s}^{-1}\right.$, Fig. 5A) the canopy best frequency, i.e. the frequency at the maximal response, is

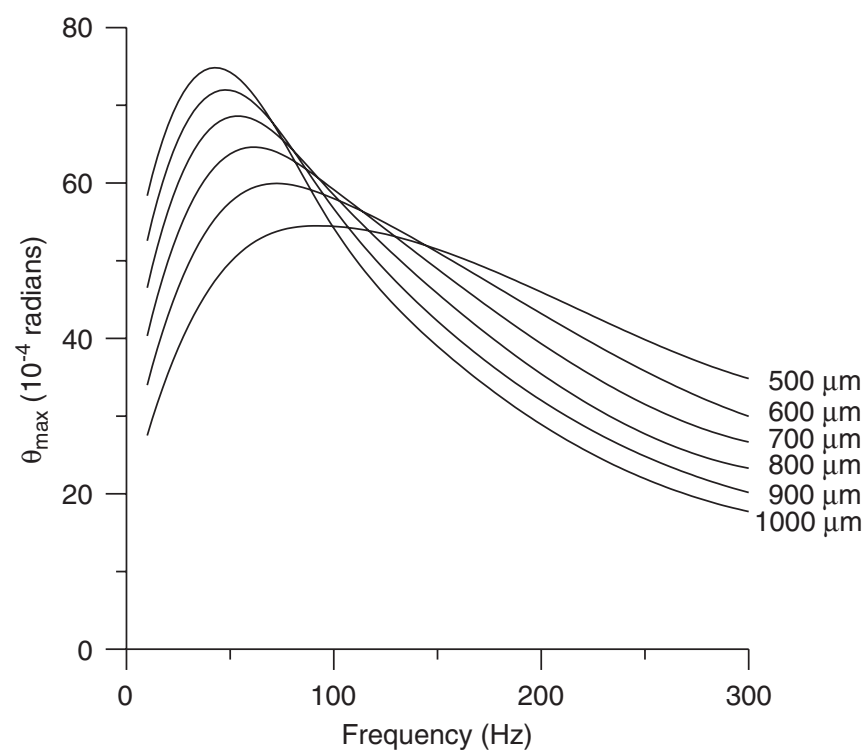

Fig. 4. Predicted maximal angular deflection of long ( $\geqslant 500 \mu \mathrm{m})$ filiform hairs as a function of stimulus frequency. Peak air velocity is $0.7 \mathrm{~mm} \mathrm{~s}^{-1}$.
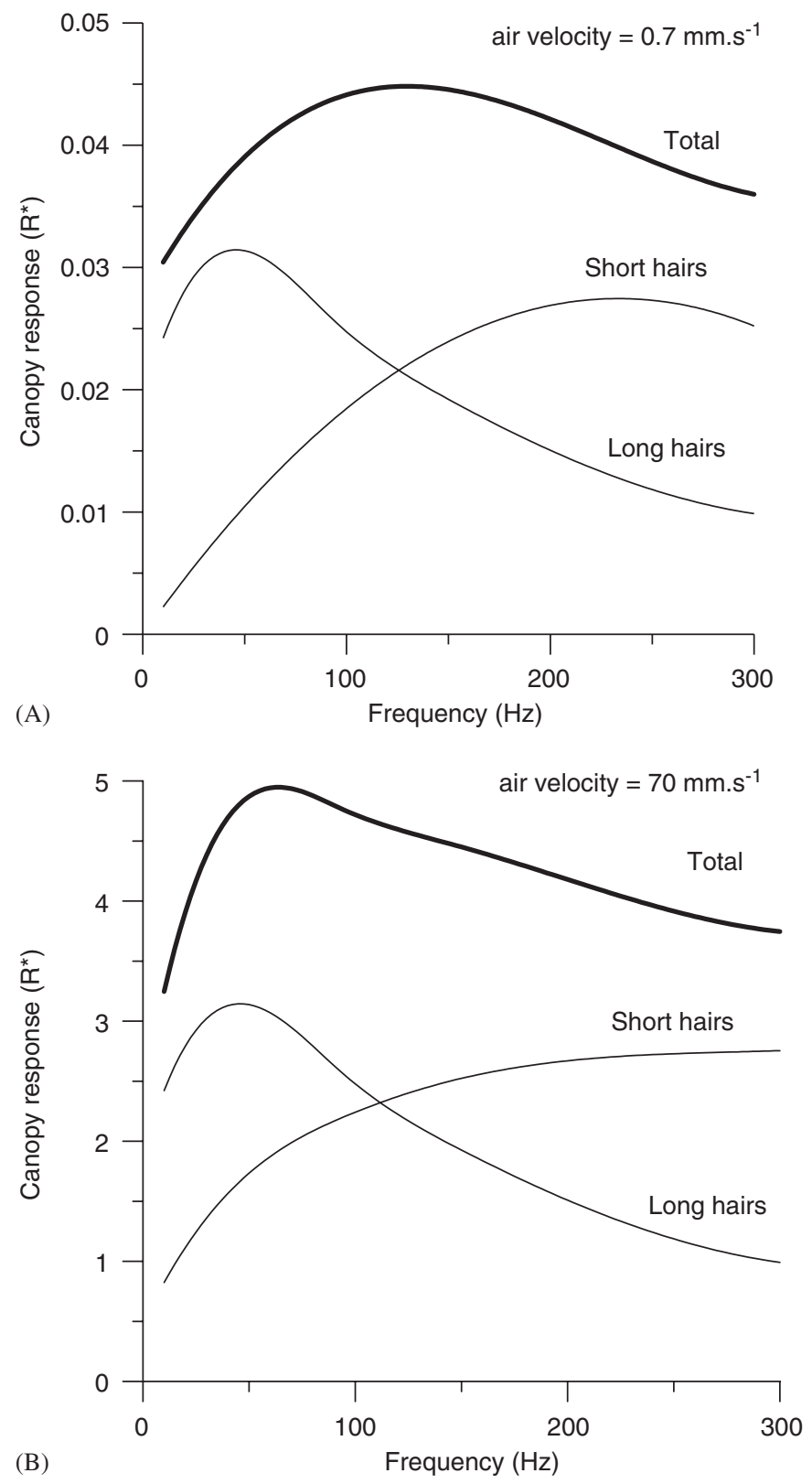

Fig. 5. Cercal hair canopy response to increasing air velocity. (A) Peak air velocity $0.7 \mathrm{~mm} \mathrm{~s}^{-1}$, (B) peak air velocity $70 \mathrm{~mm} \mathrm{~s}^{-1}$. The relative contribution of short $(<500 \mu \mathrm{m})$ and long hairs $(\geqslant 500 \mu \mathrm{m})$ is given for both situations.

high, around $140 \mathrm{~Hz}$. The number of reacting short hairs as well as the amplitude of their deflection increase with increasing velocity $\left(70 \times 10^{-3} \mathrm{~m} \mathrm{~s}^{-1}\right.$, Fig. 5B). The contribution of short hair to the canopy response increases with increasing velocity. Indeed, all long hairs are already reacting at low velocities, and only the amplitude of their deflection changes. The cercal best frequency (i.e. at peak value) thereby is lowered to $60 \mathrm{~Hz}$ and the maximal response is increased by almost two orders of magnitude. Thus, the peak response in the canopy tuning curve shifts to lower frequencies and to higher response levels with increasing air velocity. 


\section{Discussion}

Short and long hair deflexion depends on velocity and frequency of the air flux. Long hairs $\left(\geqslant 0.5 \times 10^{-3} \mathrm{~m}\right)$ react at air velocity as small as $0.03 \mathrm{~mm} \mathrm{~s}^{-1}$, whereas short hairs $\left(<0.5 \times 10^{-3} \mathrm{~m}\right)$ react at higher velocities depending on signal frequency (Fig. 2). This implies different canopy responses in shape and amplitude as a function of air velocity (Fig. 5). When air velocity increases, the canopy response increases in amplitude, but decreases in best tuned frequency until a threshold at which all short hairs react.

We used a simple summation of the maximum angular deflection of all triggered hairs. The sudden increase in canopy response at high thresholds is partly due to the reaction of many small hairs. Refined and potentially more physiological approaches could use nonlinear rules, such as the Weber-Fechner law and its modern developments. But Jacob et al. (1986) showed that a linear combination of inputs in the directional sensitivity of the cercal system was sufficient to describe neural coding. Complex but very promising approaches based on temporal spiking correlations among receptors should eventually be applied, once the appropriate data for frequency and velocity coding have been gathered for all hair classes (see, for example, Haken, 2002 for theoretical developments and Shimozawa et al., 2003 for first measurements on the cricket cercal system).

Based on partial measurements done on several individuals, Shimozawa and Kanou (1984b) suggested that the hair length distribution of $G$. bimaculatus was rather smooth and uniform. In contrast, the exhaustive measurement of the diameter of all 750 hair length inserted on the cerci of G. bimaculatus revealed a strong bimodal distribution of hair lengths, a pattern observed in a wide array of cricket species (Dangles and Casas, pers. obs.). Furthermore, hair population of $G$. bimaculatus could be divided into two main size categories, short $\left(<500 \times 10^{-6} \mathrm{~m}\right)$ and long hairs $\left(\geqslant 500 \times 10^{-6} \mathrm{~m}\right)$, which correspond to the two functionally different categories of hairs identified by Shimozawa and Kanou (1984b). This observed heterogeneity of hair length canopy has strong functional implications for cricket predator perception. Although sand crickets suffer predation from a variety of running and flying predators (Bellman and Luquet, 1995; Gnatzy, 1996), the lack of knowledge about the air flow signals produced by the first group of predators forces us to concentrate on the second one.

Both frequencies and air velocities used in our simulations are representative of natural signals produced by flying predators of crickets (Gnatzy and Kämper, 1990; Gnatzy, 1996). The dominant acoustic frequencies (around $120-200 \mathrm{~Hz}$ ) generated by flying predatory Hymenopteran and Dipteran insects (Gnatzy and Kämper, 1990; Dudley, 2000) is well within the range of tested values and include the best frequency of the cercal response. Air velocities produced by flying wasps range from several hundred microns $\mathrm{s}^{-1}$ to a few $\mathrm{cm} \mathrm{s}^{-1}$ (Tautz and Markl, 1978;
Gnatzy and Kämper, 1990), which are the values used in our simulations. These values are higher than the lowest triggering velocities reported in the introduction for single hairs, but represent likely values at which a behavioural response in the wild has been observed (Tautz and Markl, 1978; Gnatzy, 1996).

Using the main results of our model, the sensingperception sequence during a flying predator attack can be understood as follows (see Fig. 5A and B). At a large distance, air flow velocity is small and crickets detect these faint air movements through their long and sensitive hairs on one hand and many short hairs reacting near their resonance frequencies on the other hand. The cercal best frequency is therefore around $140 \mathrm{~Hz}$, a frequency noticeably higher than the resonance frequency of long hairs. Air flow velocity increases with diminishing distance between predator and prey, leading to an increasing contribution of short hair. This produces a downward shift in the cercal best frequency to $60 \mathrm{~Hz}$.

Thus, our model suggests that the highly heterogeneous hair size distribution on a cercus provides crickets a great ability to assess predatory hazards from the air as far as possible as well as at close range. The extension of this work to running predators will be possible only once their aerodynamics will be known.

\section{Acknowledgments}

This work is part of the research conducted within the Cricket Inspired PerCeption and Autonomous Decision Automata (CICADA) project (IST-2001-34718). This project is funded by the European Community under the "Information Society Technologies-IST" Programme, Future and emergent Technologies (FET), Lifelike Perception Systems action. We thank an anonymous reviewer for constructive suggestions to improve the accuracy of our model.

\section{Appendix A}

\section{A.1. Hair's moment of inertia}

According to Humphrey et al. (1993) and Kumagai et al. (1998), the total moment of inertia of a filiform hair, $I$ $\left(\mathrm{Nm} \mathrm{s}^{2} \mathrm{rad}^{-1}\right)$, is given by

$I=I_{\mathrm{h}}+I_{\mathrm{VM}}$,

where $I_{\mathrm{h}}$ is the hair moment of inertia and $I_{\mathrm{VM}}$ represents the moment of inertia of the added mass of the fluid stagnating around and moving with the hair of constant diameter

$I_{\mathrm{h}}=\frac{\pi \rho_{\text {hair }} d^{2}}{48}\left(L\left(4 L^{2}+\frac{3 d^{2}}{4}\right)\right)$,

where $d(\mathrm{~m})$ is the hair diameter, $L(\mathrm{~m})$ is hair length, and $\rho_{\text {hair }}\left(\mathrm{kg} \mathrm{m}^{-3}\right)$ is the hair density. The hair geometry is assumed cylindrical. The inertia momentum of the fluid 
added mass is given by Humphrey et al. (1993) as

$I_{\mathrm{VM}}=\frac{-\pi \mu G L^{3}}{6 g f}+\frac{\pi \rho_{\mathrm{air}} d^{2} L^{3}}{12}$.

Stokes (1851) shows that, for values of the dimensionless parameter:

$G=\frac{-g}{g^{2}+(\pi / 4)^{2}}$

with

$g=\gamma+\ln (s)$

and

$s=\frac{d}{4}\left(\frac{2 \pi f}{v}\right)^{1 / 2}$

such that $s \ll 1$, where $\gamma$ (dimensionless) is Euler's constant, $d(\mathrm{~m})$ is the hair diameter at height $y$ above the cercus, $f$ $(\mathrm{Hz})$ is the oscillating air flow frequency, and $v\left(\mathrm{~m}^{2} \mathrm{~s}^{-1}\right)$ is the air kinematic viscosity.

\section{A.2. Fluid-induced drag and added mass torques}

The fluid-induced instantaneous drag and added mass torques are obtained by integrating these forces per unit length acting along the total length of the hair, $L(\mathrm{~m})$ :

$T_{\mathrm{D}}(t)=\int_{0}^{L} F_{\mathrm{D}}(y, t) y \mathrm{~d} y$,

$T_{\mathrm{VM}}(t)=\int_{0}^{L} F_{\mathrm{VM}}(y, t) y \mathrm{~d} y$,

where $y(\mathrm{~m})$ is the position along the hair, and $F_{\mathrm{D}}(y, t)$ and $F_{\mathrm{VM}}(y, t)$ are the drag and added mass forces per hair unit length, acting at height $y$, respectively. Eqs. (12) and (13) state that the torques that act to deflect the hair from its resting position are given by the integrated sum of all torques over the arm length of rotation $y$. Each of the torques is generated on an infinitesimal thin disc of the hair shaft. Theoretical expressions for $F_{\mathrm{D}}$ and $F_{\mathrm{VM}}$, applicable to a fluid oscillating perpendicular to a constant diameter cylinder, were derived from Stokes (1851) and previously used in filiform hair modelling studies (Humphrey et al., 1993; Shimozawa et al., 1998).

\section{A.3. Drag and added mass forces per unit length}

For a fluid oscillating perpendicular to a cylindrical hair segment, the drag force acting on the cylinder at height $y$ above the cercus surface is

$F_{\mathrm{D}}(y, t)=4 \pi \mu G V_{\mathrm{F}}(y, t)$,

where $\mu\left(\mathrm{kg} \mathrm{m}^{-1} \mathrm{~s}^{-1}\right)$ is the fluid dynamic viscosity and $G$ is given by Eq. (9).
The added mass force per unit length is given by

$F_{\mathrm{VM}}(y, t)=\frac{-\pi \mu G\left(\mathrm{~d} V_{\mathrm{F}}(y, t) / \mathrm{d} t\right)}{2 g f}+\pi \rho_{\text {air }}\left(\frac{d}{2}\right)^{2} \frac{\mathrm{d} V_{\mathrm{F}}(y, t)}{\mathrm{d} t}$.

\section{A.4. Damping torque}

This torque results from the friction between the hair base and the surrounding cuticle (Shimozawa and Kanou, 1984a; Shimozawa et al., 1998). It always acts to oppose the hair motion, and the total damping torque, $T_{\mathrm{R}}$ $\left(\mathrm{N} \mathrm{m}^{-1}\right)$, is given by

$T_{\mathrm{R}}(t)=\left(R+R_{\mathrm{VM}}\right) \frac{\mathrm{d} \theta(t)}{\mathrm{d} t}$,

where $R\left(\mathrm{~N} \mathrm{~m} \mathrm{srad}^{-1}\right)$ is a constant damping factor which is allometrically related to hair length $L(\mu \mathrm{m})$ (Shimozawa et al., 1998):

$R=2.88 \times 10^{-14}\left(\frac{L}{1000}\right)^{2.77}$

and $R_{\mathrm{VM}}$ is the damping factor due to the friction between the added mass of fluid moving with the hair and surrounding air, $R_{\mathrm{VM}}$ is given by

$R_{\mathrm{VM}}=4 \pi \mu G \frac{L^{3}}{3}$.

\section{A.5. Restoring torque}

The socket joint membrane acts as a spring, causing a restoring torque that always acts as to oppose hair motion:

$T_{\mathrm{S}}(t)=S \theta(t)$,

where $S\left(\mathrm{Nm} \mathrm{rad}^{-1}\right)$ is the spring stiffness, which is allometrically related to hair length $L(\mu \mathrm{m})$ (Shimozawa et al., 1998):

$S=1.9 \times 10^{-11}\left(\frac{L}{1000}\right)^{1.67}$.

\section{References}

Barth, F.G., 2002. A Spider's World: Senses and Behavior. Springer, Berlin.

Bellmann, H., Luquet, G., 1995. Guide des sauterelles, grillons et criquets d'Europe occidentale. Delachaux et Niestlé.

Camhi, J.M., Tom, W., Volman, S., 1978. The escape behavior of the coackroach Periplaneta americana. II. Detection of natural predators by air displacement. J. Comp. Physiol. 128, 203-212.

Dayan, P., Abbott, L.F., 2001. Theoretical Neuroscience: Computational and Mathematical Modelling of Neural Systems. The MIT Press, Cambridge.

Dimitrov, A.G., Miller, J.P., 2001. Neural coding and decoding: communication channels and quantization. Netw. Comput. Neuron. Syst. 12, 441-472.

Dudley, R., 2000. The Biomechanics of Insect Flight. Princeton University Press, Princeton, NJ.

Gnatzy, W., 1996. Digger wasp vs. cricket: neuroethology of a predator-prey interaction. Inform. Process. Animals 10, 92. 
Gnatzy, W., Heusslein, R., 1986. Digger wasps against crickets. I. Receptor involved in the antipredator strategies of the prey. Naturwissenschaften 73, 212.

Gnatzy, W., Kämper, G., 1990. Digger wasps against crickets. II. An airborne signal produced by a running predator. J. Comp. Physiol. A $167,551-556$.

Gnatzy, W., Tautz, J., 1980. Ultrastructure and mechanical properties of an insect mechanoreceptor: stimulus transmitting structures and sensory apparatus of the cercal filiform hairs of Gryllus. Cell Tissue Res. 213, 441-463.

Haken, H., 2002. Brain Dynamics: Synchronization and Activity Patterns in Pulse-Coupled Neural Nets with Delays and Noise. Springer, Berlin.

Humphrey, J.A.C., Devarakonda, R., Iglesias, I., Barth, F.G., 1993. Dynamics of arthropod filiform hairs. I. Mathematical modelling of the hair and air motions. Philos. Trans. R. Soc. Lond. B 340, 423-444.

Humphrey, J.A.C., Barth, F.G., Voss, K., 2003a. The motion-sensing hairs of arthropods: using physics to understand sensory ecology and adaptive evolution. In: Barth, F.G., Schmid, A. (Eds.), Ecology of Sensing. Telos Pr., pp. 105-115.

Humphrey, J.A.C., Barth, F.G., Reed, M., Spak, A., 2003b. The physics of arthropod medium-flow sensitive hairs: biological models for artificial sensors. In: Barth, F.G., Humphrey, J.A.C., Secomb, T. (Eds.), Sensors and Sensing in Biology and Engineering. Springer, Berlin, pp. 129-144.

Jacobs, G.A., 1995. Detection and analysis of air currents by crickets. BioScience 45, 776-785.

Jacobs, G.A., Miller, J.P., Murphey, R.K., 1986. Integrative mechanisms controlling directional sensitivity of an identified sensory interneuron. J. Neurosci. 6 (8), 2298-2311.

Johnson, D.H., 2003. Limits of population coding. Proceedings of the 12th Annual Computational Neuroscience Meeting, Alicante.

Kanou, M., Schimozawa, T., 1984. A threshold analysis of cricket cercal interneurones by an alternating air-current stimulus. J. Comp. Physiol. A $154,357-366$.
Keil, T.A., 1998. The structure of integumental mechanoreceptors. In: Harrison, F.W., Locke, M. (Eds.), Microscopic Anatomy of Invertebrates. Wiley Liss, New York, pp. 385-404.

Kumagai, T., Shimozawa, T., Baba, Y., 1998. The shape of windreceptor hairs of cricket and cockroach. J. Comp. Physiol. A 183, 187-192.

Landolfa, M.A., Jacobs, G.A., 1995. Direction sensitivity of the filiform hair population of the cricket cercal system. J. Comp. Physiol. A 177, 759-766.

Landolfa, M.A., Miller, J.P., 1995. Stimulus-response properties of cricket cercal filiform receptors. J. Comp. Physiol. A 177, 749-757.

Levin, J.E., Miller, J.P., 1996. Broadband neural encoding in the cricket cercal sensory system enhanced by stochastic resonance. Nature 380 , $165-168$.

Osborne, L.C., 1996. Signal processing in a mechanosensory array: dynamics of cricket cercal hairs. Doctoral Thesis, University of California, Berkeley.

Shimozawa, T., Kanou, M., 1984a. The aerodynamics and sensory physiology of range fractionation in the cercal filiform sensilla of the cricket Gryllus bimaculatus. J. Comp. Physiol. A 155, 495-505.

Shimozawa, T., Kanou, M., 1984b. Varieties of filiform hairs: range fractionation by sensory afferents and cercal interneurons of a cricket. J. Comp. Physiol. A 155, 485-493.

Shimozawa, T., Kumagai, T., Baba, Y., 1998. Structural scaling and functional design of the cercal wind-receptor hairs of cricket. J. Comp. Physiol. A 183, 171-186.

Shimozawa, T., Murakami, J., Kumagai, T., 2003. Cricket wind receptors: thermal noise for the highest sensitivity known. In: Barth, F.G., Humphrey, J.A.C., Secomb, T. (Eds.), Sensors and Sensing in Biology and Engineering. Springer, Berlin, pp. 145-157.

Stokes, G.G., 1851. On the effect of the internal friction of fluids on the motion of pendulums. Math. Phys. Pap. 3, 1-141.

Tautz, J., Markl, H., 1978. Caterpillars detect flying wasps by hairs sensitive to airborne vibration. Behav. Ecol. Sociobiol. 4, 101-110. 